\title{
Development of transcriptome genetic markers for the great snipe (Gallinago media)
}

\author{
Robert Ekblom ${ }^{1}$ (D) Biao Wang ${ }^{1}$
}

Received: 3 April 2017 / Accepted: 10 April 2017 / Published online: 12 April 2017

(C) The Author(s) 2017. This article is an open access publication

\begin{abstract}
We sequenced the transcriptomes of 14 great snipe (Gallinago media) males from the Gåvålia study population (central Norway) using Roche 454 technology. The assembled transcriptome sequences (RNA-Seq) was used to identify 140 microsatellite repeat sequences with sufficient flanking sequence information for primer design. In addition several 1000 single nucleotide polymorphisms in the transcriptome were identified, and a small subset of these were verified by independent genotyping.
\end{abstract}

Keywords Shore bird · Molecular markers · 454 sequencing $\cdot$ Microsatellites $\cdot$ SNPs

The red listed shore bird great snipe (Gallinago media) is an ecological model species for studies of evolution of the lek mating system, sexual selection and mate choice (Höglund and Robertson 1990; Fiske et al. 1994; Sæther et al. 2005; Ekblom et al. 2010) as well as for migration research (Lindström et al. 2016). Previous genetic resources for this species have been limited to five microsatellites (SNIPE B2, 3, B5, 12 and 20; GenBank Accession numbers AY363298-AY363302; Sæther et al. 2007) and a few candidate gene sequences (Ekblom et al. 2007). This lack of large scale genetic information has severely hampered

Electronic supplementary material The online version of this article (doi:10.1007/s12686-017-0746-9) contains supplementary material, which is available to authorized users.

\footnotetext{
Robert Ekblom

robert.ekblom@ebc.uu.se

1 Department of Ecology and Genetics, Evolutionary

Biology Centre, Uppsala University, Norbyvägen 18D,

75236 Uppsala, Sweden
}

population genetic studies of this charismatic bird. Here we report on a recent large scale development of molecular markers (both microsatellites and SNP markers) using 454 transcriptome sequencing (RNA-Seq).

Great snipe males were captured for ringing using mist nets, on two active leks in the Gåvålia study population of central Norway $\left(62^{\circ} 17^{\prime} \mathrm{N}, 9^{\circ} 36^{\prime} \mathrm{E}\right)$ in the spring of 2010 (Fig. 1). For a full description of field site and methodology please see (Løfaldli et al. 1992; Fiske and Kålås 1995). Blood was taken from the brachial vein and immediately stored in RNAprotect Animal Blood Tubes (QIAGEN). RNA extractions were done using RNeasy Protect Kits (QIAGEN). Full length cDNA was synthesised using the MINT kit (Evrogen) and sequencing of cDNA libraries was performed using the Genome Sequencer FLX (Roche) technology. One full 454-plate was divided into two regions with seven samples (with individual MID tags) run on each region (Table 1). Sequencing produced more than 800,000 reads in total, with a mean of 57,000 reads per individual (Table 1). Raw transcriptome sequence reads are available at SRA (SRA060814).

After adapter- and index tag removal and quality trimming, transcriptome reads for all individuals were assembled jointly using the "cDNA mode" in GSassembler (Newbler, version 2.6, 454 Life Sciences). De-novo assembly of the Transcriptome produced 6367 contigs with an average length of 546 bp (total assembly length $3.5 \mathrm{Mbp}$; Supplementary material 1). A more detailed analysis of the gene expression levels and patterns of selection on genetic variation in expressed genes have been described in a recently published manuscript (Höglund et al. 2017).

We used msatcommander (Faircloth 2008) to identify microsatellites, searching for di- to hexa repeats in all contigs and unassembled reads. We found a total of 815 microsatellite repeat sequences in the great snipe transcriptome 

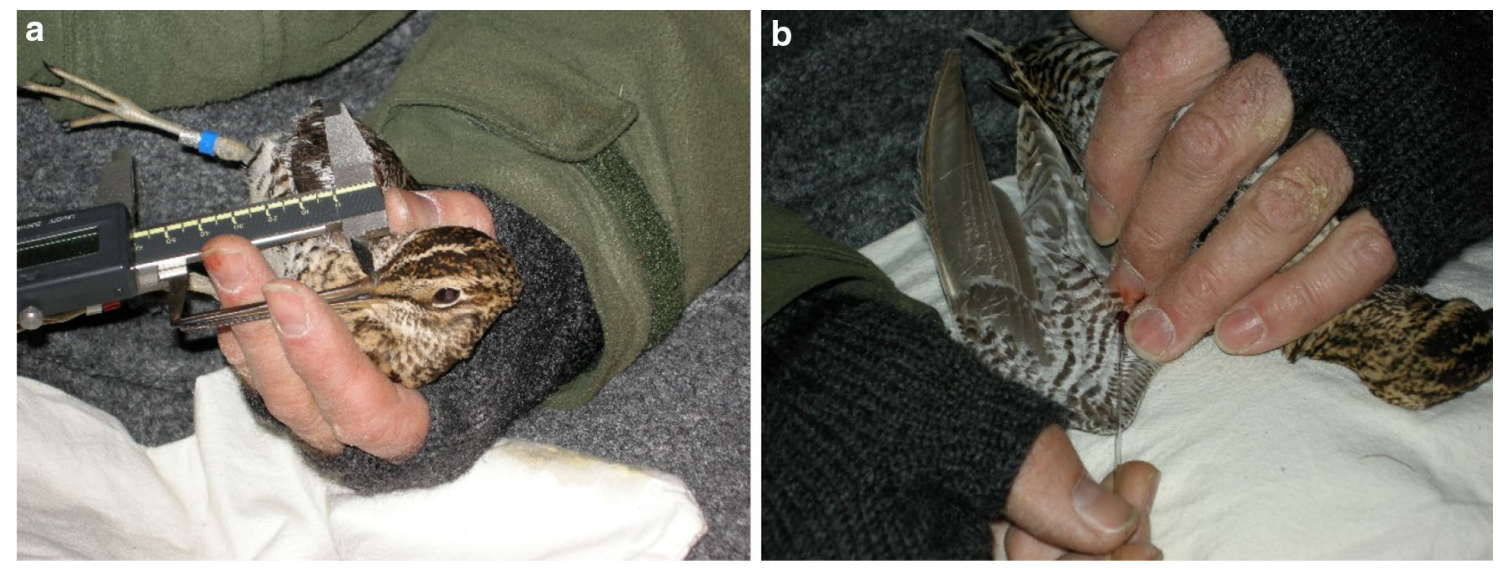

Fig. 1 Male great snipe from the study area in Norway, during ringing and blood sampling

Table 1 Summary of 454 transcriptome sequence data used in this study

\begin{tabular}{lcl}
\hline MID ID & Sample ID (ring number) & Number raw reads \\
\hline Region 1 & \\
RL1 & $3(40,396)$ & 70,255 \\
RL2 & $4(35,580)$ & 67,262 \\
RL3 & $5(40,389)$ & 43,624 \\
RL4 & $6(40,477)$ & 56,758 \\
RL5 & $8(34,749)$ & 60,950 \\
RL6 & $9(34,750)$ & 53,903 \\
RL7 & $10(34,756)$ & 32,533 \\
Region 2 & \\
RL1 & $12(35,556)$ & 63,110 \\
RL2 & $15(34,587)$ & 83,604 \\
RL3 & $16(34,781)$ & 40,644 \\
RL4 & $17(36,965)$ & 86,571 \\
RL5 & $19(40,366)$ & 58,218 \\
RL6 & $20(40,358)$ & 42,015 \\
RL7 & $23(40,404)$ & 42,803 \\
\hline
\end{tabular}

Table 2 Number of microsatellite repeat sequences identified from the great snipe transcriptome

\begin{tabular}{lllc}
\hline Type & $\begin{array}{l}\text { Minimum number of } \\
\text { repeat units }\end{array}$ & $\begin{array}{l}\text { Number of micro- } \\
\text { satellites }\end{array}$ & $\begin{array}{l}\text { Repeats with } \\
\text { primer design }\end{array}$ \\
\hline Di & 10 & 83 & 11 \\
Tri & 8 & 28 & 6 \\
Tetra & 4 & 281 & 90 \\
Penta & 4 & 272 & 29 \\
Hexa & 4 & 159 & 4 \\
Total & - & 815 & 140 \\
\hline
\end{tabular}

(Table 2). For 140 of these sufficient flanking sequence information was available to allow for PCR primer design. Detailed information about these, including repeat type and suggested primer sequences are given in Supplementary material 2.

We performed read mapping and SNP calling using GSmapper (Newbler, version 2.6, 454 Life Sciences) with the transcriptome contig file as the reference sequence. In total we identified 2874 variable positions (SNPs) in the great snipe transcriptome, 2434 of which had at least $60 \mathrm{bp}$ of flanking sequence on both sides to allow primer design for genotyping. Detailed information about these, including flanking sequences are given in Supplementary materials 3 and 4. Out of 48 evaluated SNPs, 39 were verified as true polymorphisms using independent SNP genotyping of a larger sample of individuals using the Illumina GoldenGate SNP genotyping platform (Höglund et al. 2017). Four of the tested SNPs were found to be monomorphic and five did not produce reliable genotype calls.

Two hundred and seventy eight of the SNP containing contigs were annotated using a BLAST approach, matching against chicken genome and transcriptome sequences (Supplementary material 5). Note that these described markers (both SNPs and microsatellites) are situated in transcribed parts of the genome. They are thus likely to be linked to functional genes and cannot be assumed to be selectively neutral (Ekblom and Galindo 2011).

Acknowledgements We thank John Atle Kålås, Sten Svartaas, Glib Mazepa, Mozes Blom, Claire Morandin, Jacob Höglund, Magnus Johansson, Robert Mannelqvist, Lenka Vysinkova and Urs Kormann for assistance with field work. Gavin J. Horsburgh performed RNA extractions and cDNA synthesis. Sequencing and SNP genotyping was performed at the SNP \& SEQ Technology Platform (Uppsala University, SciLifeLab). Funding for this study was provided by the Carl Trygger Foundation (CTS09:87, to RE). 
Open Access This article is distributed under the terms of the Creative Commons Attribution 4.0 International License (http:// creativecommons.org/licenses/by/4.0/), which permits unrestricted use, distribution, and reproduction in any medium, provided you give appropriate credit to the original author(s) and the source, provide a link to the Creative Commons license, and indicate if changes were made.

\section{References}

Ekblom R, Galindo J (2011) Applications of next generation sequencing in molecular ecology of non-model organisms. Heredity 107:1-15

Ekblom R, Sæther SA, Jacobsson P, Fiske P, Sahlman T et al (2007) Spatial pattern of MHC class II variation in the great snipe ( $\mathrm{Gal}$ linago media). Mol Ecol 16:1439-1451

Ekblom R, Sæther S, Fiske P, Kålås J, Höglund J (2010) Balancing selection, sexual selection and geographic structure in MHC genes of great snipe. Genetica 138:453-461

Faircloth BC (2008) Msatcommander: detection of microsatellite repeat arrays and automated, locus-specific primer design. Mol Ecol Resour 8:92-94
Fiske P, Kålås JA (1995) Mate sampling and copulation behaviour of great snipe females. Anim Behav 49:209-219

Fiske P, Kålås JA, Sæther SA (1994) Correlates of male mating success in the lekking great snipe (Gallinago media): results from a four-year study. Behav Ecol 5:210-218

Höglund J, Robertson JGM (1990) Female preferences, male decision rules and the evolution of leks in the great snipe Gallinago media. Anim Behav 40:15-22

Höglund J, Wang B, Sæther SA, Blom MPK, Fiske P et al (2017) Blood transcriptomes and de novo identification of candidate loci for mating success in lekking great snipe (Gallinago media). Mol Ecol. doi: 10.1111/mec.14118

Lindström $\AA$, Alerstam T, Bahlenberg P, Ekblom R, Fox JW et al (2016) The migration of the great snipe Gallinago media: intriguing variations on a grand theme. J Avian Biol 47:321-334

Løfaldli L, Kålås JA, Fiske P (1992) Habitat selection and diet of great snipe Gallinago media during breeding. Ibis 134:35-43

Sæther SA, Baglo R, Fiske P, Ekblom R, Höglund J et al (2005) Direct and indirect mate choice on leks. Am Nat 166:145-157

Sæther SA, Fiske P, Kålås JA, Kuresoo A, Luigujõe L et al (2007) Inferring local adaptation from QST-FST comparisons: neutral genetic and quantitative trait variation in European populations of great snipe. J Evol Biol 20:1563 